\title{
The Language of Leadership in Laos
}

\section{Peter Case}

Professor of Organization Studies

Bristol Business School

University of the West of England

Frenchay Campus

Bristol BS16 1QY

United Kingdom

Email: peter.case@uwe.ac.uk

\section{Acknowledgements}

This paper draws on research data from a project, 'Enhancing district delivery and management of extension in Lao PDR', funded by the Australian Centre for International Agricultural Research (project no: ASEM/2011/075). I would like to acknowledge financial support from ACIAR and James Cook University (with whom I have a 0.2 position as professor of management and organization studies). I am also grateful to the following project team members for indirect contributions and support: John Connell, Natalie Stoeckl, Simon Foale and Michael Jones. John Connell, an expert on Lao PDR agricultural systems, has been particularly helpful in introducing me to Lao culture(s), sharing his wide ranging experience and knowledge of the region, and assisting with my fumbling attempts to learn Lao Tai. The research methods reported in this paper have been approved by the James Cook University Human Research Ethics Committee: JCU reference H4856. In accordance with this approval, photographic images in the paper appear with verbal permission of research participants. 


\section{Introduction}

[T] he language you speak makes a difference in the social actions you can perform. The language-specific vehicle or means for an action ... will shape the action as a function of the structures it introduces. (Sidnell \& Enfield, 2012: 321)

The main purpose of this paper is to explore the relationship between the language of leadership and leadership enactments in the non-Anglophone context of Lao People's Democratic Republic (Lao PDR). As such it seeks to respond to the growing calls for studies of leadership in non-Western contexts (Turnbull et al., 2011) and the adoption of anthropological theory and method in order to enhance understanding of the subtleties of leadership relations in situated social contexts (Jones, 2005, 2006; Warner \& Grint, 2006). Some scholars have pointed out that the field of leadership studies has long been in thrall to Anglophone-centric and thus highly ethnocentric constructions of leadership (Jepson, 2009, 2010; Guthey \& Jackson, 2010; Turnbull et al., 2011). Jepson (2009, 2010), for instance, provides ground breaking insights into the social effects of leadership language in differing national contexts, contrasting the Indo-European languages of German and English. The present paper builds on this important foundation by initiating an investigation of leadership as it is conceived and enacted within Lao culture through its official language of Lao Tai. This is a direct response to the EGOS 'language and leadership' subtheme's concern with linguistically informed analysis of cross-cultural leadership phenomena. As has been pointed out by others (Kempster, 2006; Lowe and Gardener, 2000), there is a dearth of studies which examine in detail the experience of taking on and enacting leadership roles in particular contexts ${ }^{1}$. This paper is also a response to this gap in the field insofar as it offers a close empirical account of what is entailed in establishing authority and performing a leadership role in the Lao context.

Approaching the leadership from a linguistic and para-linguistic standpoint, a major premise of this paper is that language plays a constitutive role in creating 'forms of life' (Wittgenstein, 1972[1953]). In the opening quotation above, Sidnell and Enfield (2012) make a strong claim regarding the intimate link between language-as-vehicle and the shaping of social action. This generic social scientific position is commensurate with the more discipline-specific calls that Case et al. (2011) make regarding the need to pursue a research agenda that attends explicitly to linguistic aspects of leadership, focussing particularly on 
language-in-use. Furthermore, one's perceptual apprehension and understanding of every aspect of the world - one's weltanschauung (worldview) - is inexorably tied to the language one is socialized into using (Schutz, 1996[1962]; Vygotsky, 1962[1934]). The extent to which, and precisely how, language shapes thought and action are persistent and obstinate questions and have been subject to much scientific and social scientific scrutiny. One domain of contemporary enquiry that is directly relevant to the concerns of this paper relates to the problem of linguistic relativity. Put simply, the premise of linguistic relativity is that language diversity is associated (causally or otherwise) with cognitive and social diversity in differing language groups. In other words, adherents to the principle of linguistic relativity claim - in stronger or weaker terms - that language determines/influences human intention, thought and action.

While there is certainly no consensus regarding the extent, nature or effects of linguistic relativity, Sidnell and Enfield (2012) offer some fascinating insights into its development. They identify two broad stages of evolution of linguistic relativity. Firstly, there is what might be viewed as a 'classical' tradition which, influenced initially by the work of Boas (1997[1911]) and later by that of Sapir (1966[1949]) and Whorff (1967 [1956]), has spawned a primarily psychological interest in the effects of language on processes of cognition. Owing to its psychological orientation, the methodological preferences of this tradition are for laboratory experimentation (for contemporary examples, see, e.g., Levinson, 1983, 1992 1997). A second tradition of linguistic relativity emerged in the 1970s within the field of linguistic anthropology. Building on the work of Hymes (1986[1974]), Michael Silverstein set out a program for the ethnographic study of linguistic diversity and relativity (Silverstein, 1976, 1979) which focuses on indexicality, i.e., the way in which situated language-use invokes and infers context. This approach to relativity has been widely taken up within the field of anthropology (see, inter alia, Hanks, 1990: Luong, 1990).

To these two traditions of linguistic relativity, Sidnell and Enfield add a third based on their own research agenda. This third approach synthesizes ethnographically contextual understandings of language-use with the close, micro-sociological, analysis of socially situated linguistic exchanges. Informed by ethnomethodology (Garfinkel, 1967) and conversation analysis (Sacks, 1995, Sacks, Schegloff \& Jefferson, 1974, Enfield, 2009), it privileges interpretative analysis of the micro-structure of social interaction as manifest in interlocking patterns of talk. Within this version of linguistic relativity, action, identity and agency are interpreted and understood as on-going social accomplishments. To illustrate their 
third paradigm Sidnell and Enfield (2012) analyse examples of everyday social exchange in three unrelated languages: Caribbean English Creole, Finnish and Lao Tai. Amongst other conclusions, they observe:

[D]ifferences in language structure are not associated only with differences in patterns of thought or cultural context. Differences in language structure lead to linguistically relative collateral effects, which lead in turn to differences in our very possibilities for social agency. (2012: 321)

Sidnell and Enfield's interest in what they term 'collateral effects' of linguistic exchange points to the importance of the performative forces (Austin, 1976[1962]) at play in human interaction and interlocution. They suggest that the unfolding structure of exchange peculiar to a particular language grammar lock participants into bounded enactments of various sorts. During interaction, interlocutors may be pursuing personal goals over which they have a degree of choice, but these goals quickly become subservient to a structure dictated by the linguistic norms that inform mutual attributions and expectations of the social situation in question. ${ }^{2}$ Someone wanting dinner in an affluent western context, for instance, might be faced with the choice of Indian or Chinese food. Their response will lock them into differing social circumstances depending on the choice of cuisine. Moreover, there may be structurally-determined collateral effects (purely unintended consequences) which follow from the choice. For instance, if one's Anglophone mother calls by phone and says, 'you'll never guess what happened to me at the doctor's today', and you respond, 'no, what?...' you are locked into a commitment to listen to mother's story and will have to improvise socially appropriate responses to the unfolding narrative (Enfield, 2010). The performative force of 'no, what?...' is a promise to listen which is likely to have a range of other unanticipated effects.

Enfield (2010) argues that research evidence from the linguistic and anthropological record is suggestive of certain macro-level universals to human social motivation and conduct. Generic social motives would include persuading and influencing others (sometimes through conscious manipulation) to do particular things, 'helping and informing others, based on prosocial motives, and sharing experience with others to build social affiliations' (2010: 7). Such motives can be viewed as macro 'speech acts' (Austin, 1976[1962]) and have been identified and investigated by various authors (e.g., Goffman, 
1981; Hymes, 1986[1974]). Another strong candidate for universal social motive that one might add to Enfield's set is that of hierarchical positioning. As the philosopher and literary critic Kenneth Burke has pointed out, human beings are 'goaded by the spirit of hierarchy' (Burke, 1969) and pursue motives 'rotten with perfection' (Burke, 1968). The social ordering of hierarchy (as its etymology suggests) is, I suggest, crucial to any understanding of authority - and by implication, 'leadership' - relations. Indeed, I shall be paying close attention to hierarchy and authority in the examples of leadership phenomena that I discuss below in the Lao context.

Before introducing some observations on leadership in Laos based on an autoethnographic analysis of leadership practices, I shall next provide a brief overview of the agricultural reform project I am engaged on and then discuss methods employed in the study. To help key readers into my analysis of Lao leadership it is also necessary to outline some pertinent aspects of Lao PDR demographics, ethnicity and languages.

\section{Project context, research problematic and method}

Based on the Lao Government's agenda for modernization as outlined in the 7th National Economic and Social Development Plan promotes, there has been a priority given to the achievement of UN Millennium Development Goals (MDGs) for poverty reduction. In pursuit of these MDGs, the Lao Ministry of Agriculture and Forestry (MAF) has released a new Agricultural Development Strategy (ADS) for 2011-20 which promotes a transformation of MAF from an implementing agency into more of a facilitative body. The research project that I am leading is intended to assist the Department of Agriculture, Extension and Cooperatives (DAEC) - the extension arm of MAF - with this transition. Agricultural extension services in the Lao context refer to a pluralistic blend of technical advice to smallholder farmers ('farmer learning'), assisting farmers to access commercial markets for their products ('market engagement') and helping them organize groups, associations or cooperatives ('farmer organizations') to bulk products for markets and secure more favourable contracts and prices $^{3}$. Funded by the Australian Centre for International Agricultural Research (ACIAR), I and a team of researchers from James Cook University (JCU) have partnered with DAEC to design and implement a new management system to improve state-supported extension services. These services are provided in Laos by state employees (generally very poorly remunerated) via an institutional network that stretches 
outward from central government, through provincial and district offices to provide direct support to smallholder farmers across the nation. The research team is approaching this task using organization development (OD) and participant action research (PAR) methods (Chambers, 2010; Gonsalves, 2004; Gonsalves et al., 2005; Krznaric, 2007) as a means for engaging various permutations of stakeholder groups within the extension service network. Workshops are one of the vehicles we have been using to design, develop and introduce a comprehensive extension management system (EMS).

The EMS includes practical means, or what might be thought of as a 'toolkit', for decisionmaking, planning and delivery of extension services at provincial and district level. There are methods, inter alia, for: (a) identifying agricultural products that have a potential to be expanded across a given district where agro-ecological conditions are suitable; (b) selecting a product for expansion based on socio-economic scenario modelling; (c) planning activities and support at a district-wide level; and, (d) monitoring and reporting on extension activities and use of resources (including finance). The project is being implemented in two phases. Firstly, preliminary development and trialling of the EMS in four pilot districts within two provinces representing diverse agro-ecological conditions. Secondly, partnering with other NGOs and Official Development Assistance (ODA) projects in Laos to expand the use of the EMS once its usefulness and efficacy have been established. The aim is for the EMS to become integrated within the Lao agricultural service nationwide, ideally with financial support from the state, and thus to thrive well beyond the four-year life cycle of the ACIARfunded project.

While there is a decidedly pragmatic and applied action research remit to the work, this aspect of the project is not the central preoccupation of the current paper. Instead, I want to focus on anthropological instantiations of what I take to be situated leadership phenomena and uses of 'leadership language' in Lao working contexts. The leadership dynamics that I discuss, however, have a direct bearing on the likely success (or otherwise) of the extension management system interventions that are the main remit of the project.

At the time of writing, the project, for which I am designated 'leader' in the funding documentation, has been running for approximately two and a half years (November 2011June 2014). Over the course of eight field visits to Laos I have been gathering systematic ethnographic field notes and keeping a research diary of authoethnographic (Boyle and Parry, 2007; Ellis and Bochner, 2000) reflections on the experience of leading and managing a 
complex ODA initiative. Much of my time in the field thus far has been spent in meetings with the in-country project team, visiting and interacting with villagers in the project's pilot districts or attending and facilitating project workshops with in-country civil service staff. I have also kept a record of email exchanges between the James Cook University research team commissioned to work on the project and email interactions between team members and incountry project staff. In addition, the project team has undertaken a comparative literature review of agricultural extension activity in Southeast Asia (Jones et al., 2013) and collected a variety of archival material - 'grey literature' (policy documentation, development reports, etc.) - relating to the project's aims and objectives.

In this paper, my particular aim is to reflect on examples of leadership phenomena encountered whilst conducting field work in Laos. From the outset I should point out that I am not a linguist and thus far have only acquired an elementary level of speaking Lao Tai. During interactions in the field I rely heavily on co-researchers who are bilingual (English/Lao) for translation. This limits the scope of the analysis I am able to offer and the empirical claims I can legitimately make. I do not attempt in this paper, for example, to undertake a micro-sociological analysis of unfolding interactions in Lao Tai language found in the works of Enfield (2007) or Sidnell and Enfield (2012). Nonetheless, I do feel able to make a contribution to understanding the linguistic dynamics of leadership in Laos. Firstly, I have used extensive secondary resources and unstructured interviews with bi-lingual research participants to gain a deeper understanding of leadership-related terminology in Lao Tai. Secondly, I attempt to derive insights from the process both of learning the language and learning to pass as a leader in Lao working contexts. As a reasonably seasoned ethnographic researcher, spending many hours in meetings and workshops observing conduct and listening to exchanges in a language that I only partially understand has resulted in insights into many paralinguistic aspects of how leadership is accomplished on a moment-by-moment basis. As I shall explain below, taking up the role of 'project leader' in these workplace interactions has entailed learning how to respond to local expectations with respect to the deference and demeanour pertaining to that role and thus acquiring the skill of behaving like a 'credible leader'. Over the past two years I have incrementally learned 'how to pass' as a leader in workplace contexts by deploying appropriate paralinguistics and what I might call linguistic gestures. The main empirical episodes I present below are based on both ethnographic and autoethnographic field notes and insights to date. 


\section{Lao demographics, languages and ethnicity}

According to the latest census data available at the time of writing, Lao PDR has a population of about 6.4 million people ${ }^{4}$. Until the French established its borders in 1893, Laos did not exist as a nation state, so the ethnicities of people's making up this population has resulted from migration occurring over the past two millennia or so (Evans, 2002). It is estimated that there are between 50 and 200 ethnolinguistic groups represented in the population ${ }^{5}$ (Pholsena, 2006) but these are generally grouped into 5 broad families (Sisouphanthong \& Taillard 2000; Rehbein, 2007). The Tai-Kadai (also known as the Lao Loum), who dwell mostly in towns and villages in river valleys, constitute approximately $67 \%$ of the population (World Bank 2006a). These are the dominant group in linguistic, social, political and economic terms (King and van de Walle, 2010: 2). Other ethnic groups include the Mon-Khmer (21\%), who typically settled hilltop slopes, and the Hmong-Lu Mien (8\%) and Chine-Tibetans (3\%) who occupy mountaintop villages. A small fraction of the population comprises a fifth ethnolinguistic group - the Viet-Muong (Sisouphanthong \&Taillard 2000; World Bank, 2006a).

Approximately $80 \%$ of the population is engaged in agricultural production although it only accounts for circa $48 \%$ of GDP (World Bank, 2006b). The majority of Tai-Kadai occupy the lowlands of the Mekong flood plain and other river valleys where their staple crop is irrigated rice paddy. The non-Tai-Kadai, by contrast, mainly practice subsistence farming in semipermanent settlements and, in some upland locations, shifting (swidden) cultivation. Agricultural production of subsistence farmers can be very diverse as it is dependent on specific agro-ecological conditions, but typically includes upland (non-irrigated) rice, supplemented by other foodstuffs, such as, corn and other vegetables. In some locations coffee and rubber plants are cultivated, and opium poppy production is still a feature of some remote mountainous areas. Small-scale livestock rearing (typically of cattle, pigs and chickens) is also practiced by these groups. Remote upland villagers sometimes supplement diet by gathering and consuming non-timber forest products (NTFPs). These NTFPs can also be sold to traders or at town markets. Although infrastructure has certainly improved over the past two decades, many of the upland areas are difficult to reach and are poorly off in terms of school education, health and other social service provision. This disadvantage is exacerbated by non-Tai-Kadai groups having no tradition of literacy and by their not 
speaking the official Lao language. Hunger and malnutrition remains a problem in these regions and for these minority ethnic groups.

Although the project I am running has a remit to address the needs of ethnic groups other than Tai-Kadai in order to tackle problems of deprivation and malnutrition, my main focus in this paper is on the dominant (and official) Lao Tai language. This is because the civil servants we work with all speak and interact in this language, even though some of them are of different ethnicity (e.g., Hmong) and represent communities for whom Lao Tai is a second language. As my intention is to derive insights from observations of, and participation in, workplace interactions I think it reasonable to focus on Lao Tai.

\section{The 'giant slow-moving escalator': hierarchy and social positioning in Lao Tai}

What it is important to realize about Lao culture from the outset is that there is acute sensitivity to social status inscribed within linguistic and paralinguistic practices; or, at least, it is acute by comparison to Anglophone cultures. This feature of social relations is reflected structurally within the Lao Tai language and, I contend, carries fundamental ramifications for the manifestation and enactment of leadership in the workplace. In English, if one wants to report on having seen a female at a particular time and location, one might say something like, 'I met up with Susan in town today'. This phrase provides no overt clue as to my relationship to Susan and no information about our respective social statuses. An interlocutor who did not know or could not indexically infer that I am married to Susan would have to enquire further about, or pick up on, other social cues in order to work out how Susan and I are related. Even more interpretative and, possibly, interrogative work would be required to establish my social class, for example. This linguistic scenario contrasts markedly with that of a similar reference in Lao Tai. As Enfield (2010) points out in the following example, if he wants to refer to a woman called Mon 'in the market' whom both interlocutors know:

... standard practice in Lao requires me to choose from a range of title prefixes, selected according to the position of that person above or below the social line with respect to myself as a speaker. Perhaps Mon is in the grandparent category, in which case I'll refer to her as tuu-mon (tuu meaning 'grandparent'). Or if Mon is a younger sister to my father (or equivalent), I'll refer to her as qaa-mon (qaa meaning 'father's 
younger sister'). Or if she's below me - a niece or daughter or equivalent - then I'll refer to her as qii-mon, using the 'lower female' title prefix qii-. When Lao speakers make a simple reference to a person, something they must do all the time, they draw accurately and explicitly on an obligatory concern for relative social position. (2010: 11, amended transliteration of the Lao Tai)

Several European languages draw distinctions between polite and familiar second-person ('you') references. For example, there are the polite forms Sie and vous, respectively, in German and French, which contrast with the more familiar $d u$ and $t u$. A relatively sophisticated knowledge of these languages and cultures is required before the references can be deployed confidently and without potentially giving offence. In Lao-Tai both first-person and second-person reference is a far more baroque process when compared with the socially anodyne 'I/you' of English or even the Ich/Sie/du or je/vous/tu of German and French respectively. There are four ways of referring to 'I', 'you', 'she/he' each of which index respective social positioning and status differentials between the speaker and interlocutor and/or the speaker and person being referred to (see Table 1 for a summary).

\begin{tabular}{|l|l|l|l|}
\hline & I & you & she/he \\
\hline Bare & kuu & mùng & man \\
\hline Familiar & haw & Too & law \\
\hline Polite & khoi & caw & phen \\
\hline Formal & $\begin{array}{l}\text { khaa- } \\
\text { phacaw }\end{array}$ & thaan & thaan \\
\hline
\end{tabular}

Table 1. Lao personal pronouns (singular forms) adapted from Enfield (2010: 10)

Enfield (2010: 10) illustrates the linguistic complexity wonderfully well by invoking an escalator simile:

We know from the ethnographic record that Lao speakers have a variegated and uneven social world. It is as if each person is on a giant slow-moving escalator, where everyone else is either above or below you, and your relative position gets higher as 
you get older. Only a few others fit on the same step as you, for example those born in the same year, who you've known since early childhood. The positions of other people have to be monitored carefully in daily life.

I have experienced this 'slow-moving' escalator first hand on many occasions whilst working in Laos, although it has taken me time and repeated experience to recognize it. When meeting a Laotian for the first time they will be eager to establish a sense of their relative social position in relation to you (the other). This status differential can be based on many things but, typically between strangers, is governed by gender and age. Where the differences are not readily apparent, then a kind of social dance can ensue. One strategy I have adopted to get around this is to introduce myself as 'ajarn Peter' (khoi suur ajarn [my name is professor] Peter), where the prefix ajarn denotes 'teacher' as, in my case, 'university professor'. This quickly settles the matter in most instances and interactions can proceed with relative social status having been established.

\section{The language of leadership in Laos}

Strictly speaking, there is no such thing as leadership in Laos. By this I mean that in Lao Tai, as in very many other languages, there is no equivalent to the English adjective 'leader-ship' (Case et al., 2011). There are certainly terms that equate more or less to the English word 'leader'. These would include such expressions as: nai baan (village head); hua nā (a term ubiquitously used in the workplace to refer to the 'boss'); jeol muang (the term for 'district governor' - jeol meaning 'prince' and thus having etymological roots in the now archaic period of pre-colonial rule under the so-called 'mandala' system; muang referring to a region or district); and neo hom (village elders - a term, again, which has deep cultural legacy within the complex kinship relationships and hierarchies of Lao village communities).

Based on unstructured conversations with Mr Phouvong ${ }^{6}$ (a senior civil servant within the Ministry of Agriculture and Forestry) and other in-country staff involved with our project, I have learned that terms for 'leader' are used exclusively in relation to members of the Lao People's Revolutionary Party (LPRP). In other words, formal leadership roles are solely occupied by Party members and ordered according to strict hierarchical positions. Nobody outside the Party can be considered to have leadership status. According to my informants, 
between 3-5\% of the Lao population are members of the Party, moreover, and its formal influence stretches from the highest levels of Government - the president, prime minister and deputies - through ministerial and departmental layers of hierarchy outward into the 17 provinces, 144 districts and, ultimately, thousands of villages. Village heads (nai baan) and elders (neo hom) will invariably also be LPRP members. Provincial governors (jeol khwang) and district governors (jeol muang) are also leaders occupying relatively powerful positions and licenced to make decisions within Government policy frameworks; decisions which can shape and have major effects on activities and livelihoods within their regional jurisdictions.

From an emic perspective ${ }^{7}$, then, there is no sanctioned 'leadership' outside of the LPRP hierarchical structure. The military-like structure and process of the party, an historical legacy (Zasloff, 1973), facilitates and promotes a command and control approach to decision making. Policy is operationalized at differing levels of the LPRP system and, in effect, orders are issued to achieve particular targets within particular time frames. One outcome of this structural form and the dominance of position power in Laos is that people outside the Party feel inhibited and unable (because of likely sanctions) to come up with new ideas, to innovate or to pursue initiatives that are not formally sanctioned. In other words, there is a widespread sense in which non-Party members are reluctant to put their head above the parapet, so to speak. Their position in society does not encourage the pursuit of independent initiative and 'the system' does not incentivize them to change procedures and practices in their work contexts. This reflects, perhaps, the glacial nature of change in with the LPRP itself whose Central Committee comprises a highly stable elite who attain power through patronage and/or familial connections with figures who held senior positions at the time of the revolution (Taylor, 2012).

\section{Official meetings: the paralinguistics of leadership}

When visiting Laos in an official capacity, my project work is typically split between (a) participating in, or facilitating, official workshops (b) field visits to various district sites to monitor progress of the Extension Management System (EMS) implementation and (c) visits to villages to garner farmers' perceptions of how well they are being supported by project activities and what changes in practice, if any, have occurred. When interacting with incountry staff on these occasions I have, over the past two years of so, become aware of the 
need to perform the role of leader as this would be understood in the Lao context. In other words, I have taken it upon myself to learn, in ethnomethodological terms (Garfinkel, 1967), how to pass as a proxy hua nā. Having to work through a translator constrains my ability to do this linguistically, so, instead, I have observed other aspects of leadership demeanour and tried to adopt and enact suitable behaviours. Of course, I am neither a member of the LPRP nor do I occupy an official position within the civil service. I cannot, therefore, benefit from automatic attributions of authority from civil service staff. And yet, as I have learned, in order for the JCU project to get traction in the hearts and minds of in-country staff, it is imperative in certain formal working contexts that I 'come over' as a credible figure of authority.

As mentioned above, participant action research workshops are the primary means by which the project team introduces the EMS, develops plans in collaboration with staff and monitors project progress. These events tend to be medium-sized gatherings involving 20-30 participants and typically last three to four days. Thus far they have been hosted alternately in the project's two pilot study provinces - Xienkhuang and Borlikhamxay - and located in

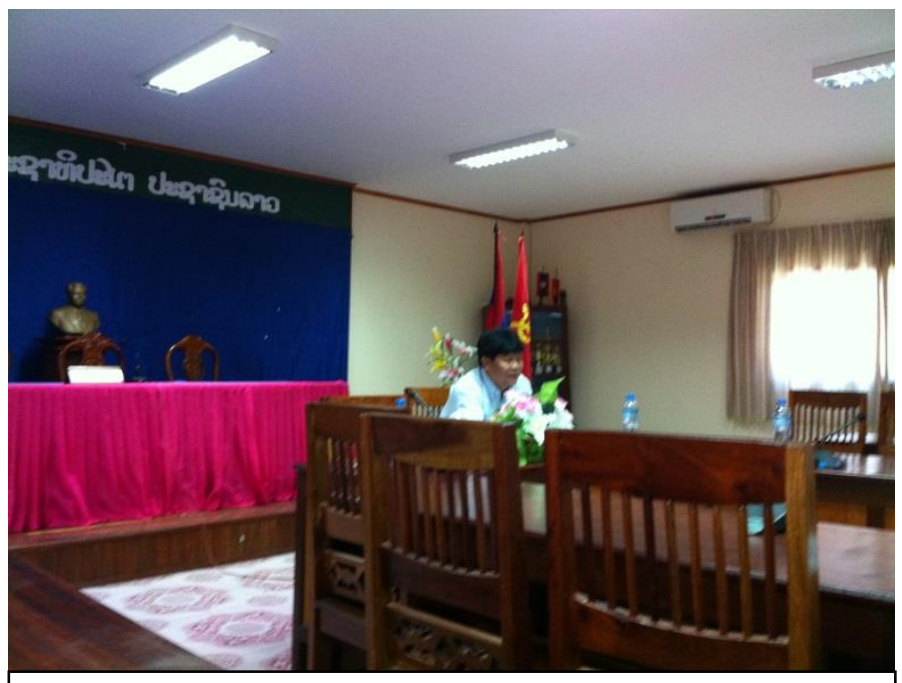

Figure 1. The lone hua nā: a senior civil servant chairs a meeting in Borlikhamxay Provincial Agriculture and Forestry Office. local government buildings or hotels. In addition to these major workshop events, the JCU and DAEC project teams also hold interim meetings on a smaller scale to pursue various operational tasks. The kinds of protocols and forms of authoritydisplay described below, however, are also evident in these smaller gatherings. Room and seating configuration during the major workshops are standardized regardless of whether they are convened in an

official building or a hotel. Figures 1 and 2 give an indication of the typical room layout: long hardwood tables and chairs, arranged in two parallel rows running the length of the room, with a table running crosswise at one end at which presides the hua nā for key parts of proceedings. Although there is plenty of scope for working in smaller groups, workshops follow certain procedural protocols which seem not to vary greatly. These include an opening speech by the most senior person or persons present; a prosaic outline of the workshop 
purpose and programme; formal discussions chaired by the most senior official present at the time (with open discussions typically being preceded by contributions from the floor that are taken in order of seniority, e.g., Provincial Agriculture and Forestry Office (PAFO) Heads, followed by District Agriculture and Forestry Office (DAFO) Heads); and a 'closing' process which entails a prosaic summary of the key elements of the programme and relating an official version of 'what has been achieved', followed by closing speeches by the most senior staff present.

Figure 1 is a photograph of a senior official from the Ministry of Agriculture and Forestry presiding at workshop proceedings in a PAFO meeting space. Immediately behind the head

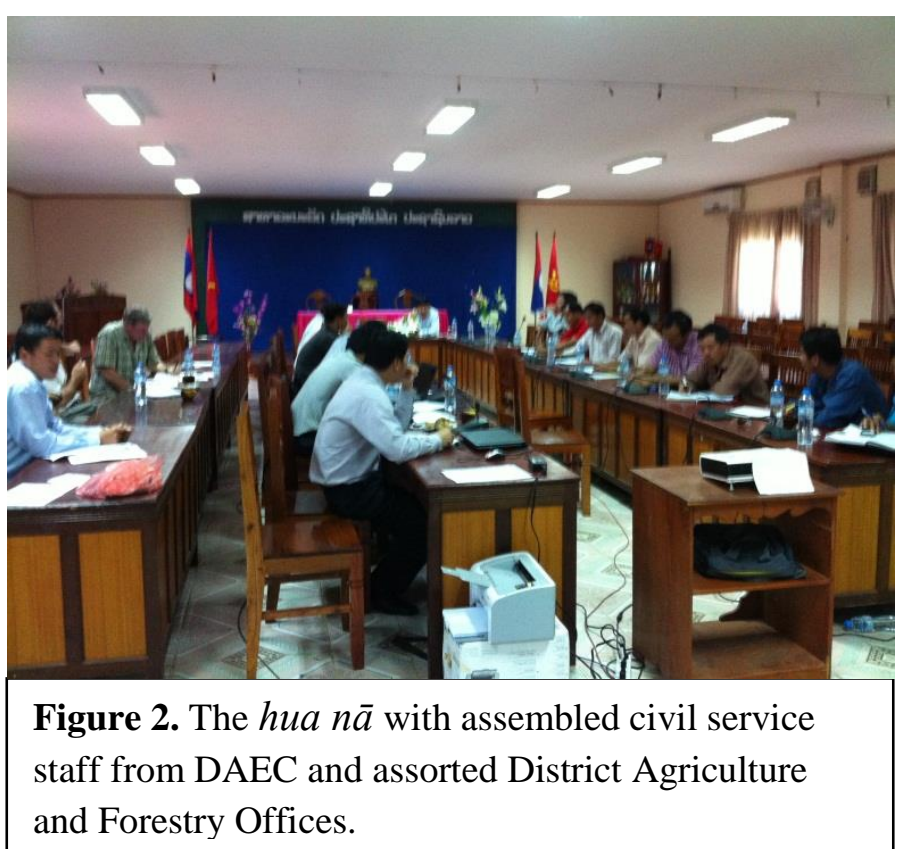
of this hua $n \bar{a}$ are two flags: the communist hammer and sickle alongside (a slightly obscured) Lao national flag. To the far left centre can be seen the bust of Kaysone Phomvihane, leader of the LPRP from 1955 onwards and the country's first Prime Minister (1975-1991) and first President (1991-2) ${ }^{8}$. Physical artefacts, such as, the flags and the bust carry symbolic significance and set a particular tone for the activities and verbal exchanges that take place in this space. Figure 2 offers another perspective on the same space, this time showing the placement of other participants in relation to the hua nā and each other. The inner tables have places reserved for more senior members of staff, for example, PAFO and DAFO Heads, whereas the outer tables in the parallel rows are occupied by more junior members of staff. Members of the DAEC and JCU project teams also occupy space on the outer tables. This positioning has more to do with the practicalities of organizing workshop activities and distributing documentation than as a performative statement of relative hierarchical authority. For example, being located on the outer table permits the organizers ease of access to the computing and printing technologies pictured in the foreground of Figure 2. 
There are thus significant dramaturgical and practical organizational aspects to the physical configuration of the meeting space. The presence of key symbolic artefacts and the arrangement of certain participants in the room carry meaning in terms of the social order (hierarchical ranking) as well as spatially configuring interactions. In my continuing efforts to 'pass' as a proxy hua nā, I have learned to occupy a chair at the head of the table alongside the other most senior staff in the room for the most symbolically critical moments of workshop meetings; typically 'openings' and 'closings'. Authority is marked, in part, by having the first and last word at the official event. Where possible, I have also tried to invite a bilingual senior ministry official to translate for me, again with the explicit intention of establishing credibility in the eyes of participants with respect to the hierarchical order and hence to the importance of what I and, by association, members of my team have to say.

Dress code is also an important consideration. What, in the West, we might describe as smart casual summer wear is the norm so, as with other considerations, I am careful to ensure that my apparel is appropriate. There appears to be no observable and obvious difference between the clothing worn by senior and junior staff, although I have noticed that some of the most senior officials have a penchant for high-collared black jackets with zip-up fronts. An example can be seen in Figure 3, worn by the participant second from left.

Participants are also in the habit of demonstrating attentiveness by the taking of notes in what presents as an earnest and meticulous fashion. This is the case particularly in plenary when the opening and closing speeches are being made or when senior staff make a comment. During the meeting pictured in Figure 3, for example, I noticed several of the participants busily scribbling notes when my opening remarks were being translated.

Another feature of plenary meetings is the ceremonial use of clapping to demonstrate approval of what has been said. Opening and closing speeches by senior staff, for example, will invariably be met with applause. Similarly, if someone makes an extended comment from the floor during discussions it is quite often received with a round of clapping. This can be more or less enthusiastic depending on the perceived salience and degree of approbation of the audience. 


\section{On becoming a hua $n \bar{a}$}

My efforts to pass as a proxy hua nā came to the fore during a recent field trip (year two of the project) where it was necessary for me to chair a meeting. Up until this point, my role in

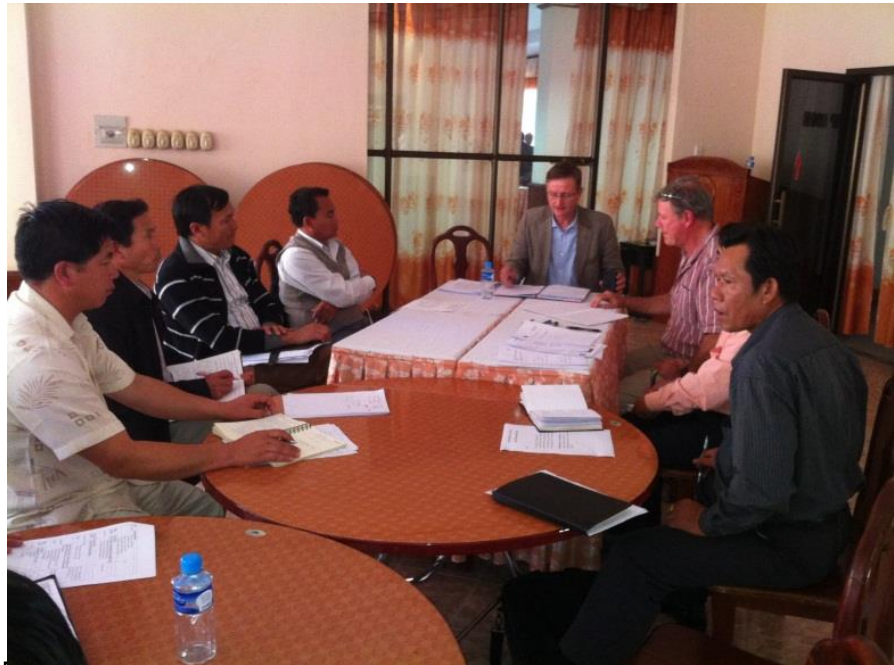

Figure 3. The author as proxy hua nā: chairing a meeting of Heads of District Agriculture and Forestry Offices in Paksan. proceedings had been more

ceremonial than functional, as it were. As described above, I had given short opening and closing speeches during full workshop proceedings, as well as making presentations and answering questions about the project. The episode I am about to describe, however, marked the first time I had attempted to perform a more extensive leadership role. Figure 3 pictures a group comprising Heads of DAFO (these would all be LPRP members) at

a meeting convened by me to discuss expansion of the EMS to other districts in the pilot provinces. Representatives of these 'new' districts were present alongside those Heads who had already been trialling the management systems. I can be seen, top centre, chairing the meeting and to my right in the photo is John Connell, the JCU agricultural extension specialist, who is acting as translator. I deliberately configured the room and chair placement to replicate that of the many other meetings in Laos that I had attended and observed. Furthermore, as I had come to learn, I began the meeting with a resolute-sounding speech extolling the virtues and importance of the work we were doing for the people of Laos and emphasising the crucial role to be played by DAFO Heads in achieving our collective objectives of improving smallholder livelihoods. Even though delivering this in English and thus not being understood by anyone in the group, I nonetheless used a forceful tone of voice of the sort I had heard other Lao leaders employ for this kind of rousing talk. Content was translated by my colleague John. Following this speech, I then took firm control of the turntaking from the floor, deliberately inviting comment from particular individuals (for example, starting with a request for feedback from the expansion district Heads on their impressions of the workshop and exposure to the EMS thus far). As I had seen other hua $n \bar{a}$ do, I was careful to interpret and 'edit' responses, so that, wherever possible, comments from participants 
could be brought back into an overarching frame of the project aims and objectives. The discussion followed an agenda that I had prepared first in English and then asked one of the bilingual in-country project team members to translate.

During this meeting, we encountered a particularly interesting leadership issue arising from the translation of an expression for 'district-wide plans'. In response to my request to report, the Head of DAFO from Nong Het (a pilot district in Xiengkhuang province) was discussing how he felt about the district-wide planning process, pointing out that this had many advantages and that in Nong Het clear progress had been made towards improvements in expansion of black-fleshed chicken (gai-sin-dham) production. He referred to the planning process using a phrase for 'master plan', an expression which is used in common parlance within the Lao civil service. My colleague, John Connell, translated the phrase master plan song-serm to me as 'master plan' (the Lao simply use the English word 'master plan' and, in this case, it is qualified by song-serm, meaning to 'support improvement'). I picked up on this and queried the term with John as I noticed that the group responded visibly and affirmatively to the use of this expression. It was something that they quite evidently could all comprehend and that seemed to pique their interest. Up until this point in PAR workshops, we had been repeatedly referring to the need for the DAFO staff to focus on developing 'district-wide plans' expressed as pan song-serm tua muang [plan for extension across the districts], or pan song-serm rudup muang [plan for extension at the district level]. These terms were simply coined by JCU team members who were fluent in Lao Tai with the expectation that these would be appropriately descriptive. None of the in-country participants ever explicitly challenged what was meant by these phrases, or ever suggested any alternatives. This was the case even within the central departmental DAEC team, so the JCU researchers simply took it for granted that these expressions were self-explanatory. Typically, when speaking about district-wide plans in plenary discussions or presentations, JCU staff would refer to accompanying maps of the relevant districts to illustrate specifics of the production areas in question with a view to visually reinforcing the meaning and centrality of pan song-serm tua muang within the project context.

In the initial phases of the project and, more specifically, during the first round of workshops A0 maps were used with participants as part of a 'product opportunity identification' process (what we referred to in shorthand as 'EMS 1'). When we spoke of district-wide planning in terms of pan song-serm tua muang or pan song-serm rudup muang the JCU team were 
puzzled by the fact that DAFO staff still expressed their expansion objectives incrementally by way of enrolling, for instance, an additional five or six villages rather than thinking on a grander scale; supporting commercial production of, say, a new rice variety across sixtyseventy new villages. The incremental thinking became a point of contention and the JCU team encouraged participants to reconsider their plans and identify ways in which a given product, $\mathrm{x}$, could be scaled-up across an entire district. What from the etic perspective of the outside 'experts' appeared to be 'confusion' on the part of DAFO staff, may have resulted, the researchers inferred, from them falling back on habitual ways of working (i.e., they were used to offering purely technical assistance on a small scale). During the DAFO Heads meeting described above, however, it suddenly became apparent that translation could well have played a crucial part in mutual misunderstanding and incomprehension. Until this catalytic moment, our reference to pan song-serm tua muang [ plan for extension across the districts] pan song-serm rudup muang [plan for extension at the district level] were, in effect, operating as project-specific linguistic artefacts that participants simply 'went along with' without really 'getting the point'. Staff complied with our requests, particularly when we introduced a way of modelling economic scenarios for up-scaling of projects (something we referred to as 'EMS 2') but appeared not to integrate the practice into their everyday ways of working. It was something peculiar to 'the project'. When our colleague from Nong Het started speaking in terms of master plan song-serm we accidentally alighted upon a phrase that participants could readily grasp and relate to. It was as though a light was suddenly switched on in participants' minds.

It remains to be seen whether or not use of the expression master plan song-serm will be a turning point in understanding. At the time of writing it is simply too early to tell. As noted above, the English expression 'master plan' has been adopted into the Lao Tai bureaucratic lexion. In-country staff will associate master plan song-serm with similar expressions, such as, pan haa pii [five-year plan] which was introduced during the era of Soviet Russian influence on the LPRP. But this connotation brings with it another set of prospective difficulties. The pan haa pii is typically known by those expected to implement it to be highly aspirational and abstract in nature. These types of planning processes are undertaken routinely but are almost always under resourced and hence seldom, if ever, likely to yield the planned outcomes. Staff would come to see the pan haa pii as a ceremonial exercise undertaken in the agricultural context with little expectation of success and thus a rather empty exercise ${ }^{9}$. So the leadership language of master planning may well carry some 
historical baggage even though it has the advantage, in project terms, of being familiar to staff. Again, at this point it remains to be seen whether the terminology will assist achieving results in terms of changing farmer practices, enabling farmers to get better yields, bulk their produce and secure greater incomes.

\section{Conclusions}

In writing this autoethnographic account of 'becoming hua nă' I am aware that the deliberate posturing and conscious manipulation of self-presentation might readily be interpreted as acts of crass egocentric indulgence on my part. Acknowledging that one can never fully discount the presence of sub-conscious narcissistic motives of this sort pressing their way to the surface, this is certainly not how my conscious mind construes its attempts to garner authority in this Lao working context. On the contrary, as an academic who would prefer to shun rather than embrace expressions of authority, I feel decidedly uncomfortable with the histrionics I have related above and their intended power effects. However, the choices of action I describe are made in the acquired knowledge that, were I not to fashion a performance of this sort, the day-to-day project activities and intended practical outcomes could be significantly compromised. I invite the reader to take it on trust that my underlying intentions were geared toward improving the chances of project success (whatever that might eventually mean). The motives underlying these intentions, in turn, are premised on an ethical assessment of the overall worth and likely 'positive effects' on smallholder well-being of the project interventions. Such intentions and motives are, of course, contestable and it remains a distinct possibility that others (and perhaps I, at a later date) may judge them to be misguided.

My aim in this paper was to respond to calls in the leadership studies field for empirical studies of leadership processes in non-Anglophone contexts and those which pay close attention to the adoption and enactment of leadership roles. I began by reviewing some of the salient literature on linguistic relativism and set out reasons why it is important to explore the relationship between language, thought and social organization when studying leadership phenomena. To explore and expose aspects of the language of leadership in Laos, I set out the project context within which my field work and data were collected and also explained some of the main features of the ethnic and linguistic variation in this region. The focus of my study was twofold: (a) a study of certain key linguistic aspects of person reference and 
leadership terms in Lao Tai; and, (b) a micro-sociological account of how leadership is accomplished in particular work contexts in Laos. The operation of hierarchy is of central importance linguistically in Lao Tai and I argued that this translates into the operation of hierarchical authority in leadership relations within a system dominated politically and socially by the workings of the LPRP. Making reference to ethnographic and autoethnographic field notes, I attempted to provide an account of how my role of 'project leader' necessitated the conscious learning and adoption of the behaviours associated with being a hua nă (boss). In other words, I found myself having to learn how to accomplish authority in ethnomethodological and dramaturgical terms. There was a decidedly practical motive underlying this attempt on my part to become hua nă. Establishing and exercising authority in this way was intended to enhance the chances of the 'extension management system' being successfully taken up and employed by agricultural extension staff in Laos.

Future research will build on this paper to examine how the peculiarities of authority relations in Laos have contributed to the emergence of certain project-specific leadership lacunae. The aim will be to expose 'limitations' to the deployment of Western organization development methodology and interventions in the Lao context, characterized as it is by authoritarian forms of bureaucratic command and control.

\section{References}

Austin, J. L. (1976[1962]) How to Do Things With Words, Oxford: Oxford University Press.

Bartlett, A. (2011) A short history of agriculture extension in Lao PDR. [On-line, available at http://www.laofab.org/document/view/1629, accessed 14.07.13].

Boas, F. (1997[1911]) Handbook of American Indian languages. London: Routledge/Thoemmes Press.

Boyle, M. and Parry, K. W. (2007) Telling the whole story: The case for organizational autoethnography, Culture and Organization, 13(3): 185-90. 
Burke, K. (1969) A grammar of motives. London: University of California Press.

Burke, K. (1968) Attitudes toward history. London: University of California Press.

Case, P., French, R. \& Simpson, P. (2011) The philosophy of leadership. In A. Bryman, D. Collinson, K. Grint, B. Jackson and M. Uhl-Bien (eds) Sage Handbook of Leadership, pp. 242-254. London: Sage.

Chambers, R (2010) Paradigms, poverty and adaptive pluralism. Institute of Development Studies Working Paper 344, Brighton, UK: University of Sussex.

Dictionary of Lanaguages (2004) 'Lao'. Online: Credo References

[http://search.credoreference.com.elibrary.jcu.edu.au/content/entry/dictlang/lao/0 Accessed 9.01.14].

Ellis, C. and Bochner, A. (2000) Autoethnography, personal narratives, reflexivity:

Researcher as subject. In N. Denzin, and Y. Lincoln (eds) Handbook of Qualitative Research (3rd ed.), pp. 1-32. London: Sage.

Enfield, N. J. (2009) The anatomy of meaning: speech, gesture, and composite utterances. Cambridge: Cambridge University Press.

Enfield, N. J. (2010) Human sociality at the heart of language. Inaugural lecture, Nijmegen, The Netherlands: Radboud University.

Evans, G. (2002) A short history of Laos: The land in between. Crows Nest, N.S.W: Allen \& Unwin.

Garfinkel, H. (1967) Studies in ethnomethodology. New Jersey: Prentice-Hall.

Goffman, E. (1981) Forms of talk. Oxford: Blackwell.

Gonsalves, J. (2004) Participatory Research and Development for Sustainable Agriculture and Natural Resource Management: a Sourcebook, Volume 2: Enabling Participatory Research and Development. Ottawa: IDRC Books/Les Éditions du CRDI. 
Gonsalves, J., Becker, T., Braun, A., Campilan, D. and de Chavez, H. (2005) Participatory Research and Development for Sustainable Agriculture and Natural Resource Management: a Sourcebook, Volume 3: Doing Participatory Research and Development. Ottawa: IDRC.

Guthey, E. and Jackson, B. (2011) Cross-cultural leadership revisited. In A. Bryman, D. Collinson, K. Grint, B. Jackson and M. Uhl-Bien (Eds.) The SAGE Handbook of Leadership. London: Sage, 165-178.

Hanks, W. F. (1990) Referential practice: language and lived space among the Maya. Chicago: University of Chicago Press.

Harris, M. (1976) History and significance of the emic/etic distinction. Annual Review of Anthropology, 5(1): 329-350.

Hymes, D. (1986[1974) Foundations of sociolinguistics: an ethnographic approach. Philadelphia, PA: University of Pennsylvania Press.

Jepson, D. (now Schedlitzki, D.) (2009) Studying leadership at cross-country level: A critical analysis. Leadership, 5(1), 61-80.

Jepson, D. (now Schedlitzki, D.) (2010) The importance of national language as a level of discourse within individuals' theorising of leadership - A qualitative study of German and English employees. Leadership, 6(4): 425-445.

Jones, A. (2005) The anthropology of leadership: Culture and corporate leadership in the American south. Leadership, 1(3): 259-78.

Jones, A. (2006) Developing what? An anthropological look at the leadership development Process. Leadership, 2(4): 481-98.

Jones, M., Case, P. and Connell, J. (2013) Comparing developments in agricultural extension services in Lao PDR with global trends: a literature review. Canberra, ACT: ACIAR.

Kempster, S. J. (2006) Leadership learning through lived experience: A process of apprenticeship?, Journal of Management and Organization, 12(1): 4-22. 
Kempster, S. and Stewart, J. (2010) Becoming a leader: A co-produced autoethnographic exploration of situated learning of leadership practice. Management Learning, 41(2): 205219.

King, E. M. and van de Walle, D. (2009) Laos: Ethno-linguistic diversity and disadvantage. In G. Hall and H. Patrinos (eds) Indigenous peoples, poverty and development. Washington:

Georgetown University [available on-line at:

http://siteresources.worldbank.org/EXTINDPEOPLE/Resources/4078011271860301656/full_report.pdf, accessed 10.01.14].

Krznaric, R (2007) How Change Happens: Interdisciplinary Perspectives for Human Development. Oxfam Research Report. Oxford: Oxfam GB Publications.

Levinson, S.C. (1983) Pragmatics. Cambridge: Cambridge University Press.

Levinson, S.C. (1992) Primer for the field investigation of spatial description and conception. Pragmatics 2(1):5-47.

Levinson, S.C. (1997) Language and cognition: the cognitive consequences of spatial description in Guugu Yimithirr. Journal of Linguistic Anthropology 7(1):1-35.

Lowe, K. B. and Gardner, W. (2000) Ten years of The Leadership Quarterly: Contributions and challenges for the future, Leadership Quarterly, 11(4): 459-514.

Luong, H. V. (1990) Discursive practices and linguistic meanings: the Vietnamese system of person reference. Amsterdam: Benjamins.

Parker, M. (2004) Becoming manager or, the werewolf looks anxiously in the mirror, checking for unusual facial hair. Management Learning, 35(1): 45-59.

Pholsena, V. (2006) Post-war Laos: the politics of culture, history, and identity. Ithaca, NY: Cornell University Press.

Pike, K.L. (1993) Talk, thought and thing: the emic road toward conscious knowledge. Summer Institute of Linguistics, Dallas, Texas [available at: http: www.sil.org/klp/ttt/title.html]. 
Rehbein, B. (2007) Globalization, Culture and Society in Laos. London: Routledge.

Sacks, H. (1995) Lectures on conversation, 2 volumes. Oxford: Blackwell.

Sacks, H., Schegloff, E. A. and Jefferson, G. (1974) A simplest systematics for the organization of turn-taking for conversation. Language 50(4): 696-735.

Sapir, E. (1966[1949]) Language, culture and personality. London: University of California Press.

Schutz, A. (1996 [1962]) Collected papers, volume 1: The problem of social reality. The Hague: Kluwer.

Sidnell, J. and Enfield, N.J. (2012) Linguistic diversity and social action: A third locus of linguistic relativity. Current Anthropology, 53(3): 302-332.

Silverstein, M. (1976) Shifters, linguistic categories, and cultural description.

In K.H. Bassi \& H.A. Selby (eds) Meaning in anthropology, pp. 11-

55. Albuquerque: University of New Mexico Press.

Silverstein, M. (1979) Language structure and linguistic ideology. In P.R. Clyne, W.F. Hanks \& C.L. Hofbauer (eds) The elements: a parasession on linguistic units and levels, pp, 193247. Chicago: Chicago Linguistic Society.

Sisouphanthong, B. and Taillard, C. (2000) Atlas of Laos: Spatial structures of the economic and social development of Lao People's Democratic Republic. Copenhagen, Denmark:

NIAS.

Taylor, R. (2012) Lao politics in transition? Unpublished manuscript.

Turnbull, S., Case, P., Edwards, G., Jepson, D. and Simpson, P. (2011) Worldly Leadership. London: Palgrave.

Vygotsky, Lev S. (1962 [1934]) Thought and language. Cambridge, MA: MIT Press. 
Warner, L.S. and Grint, K. (2006) American Indian ways of leading and knowing.

Leadership, 2(2): 225-44.

Whorf, B.L. (1967[1956]) Language, thought and reality: Selected writings. Cambridge, MA: MIT Press.

Wittgenstein, L. (1972 [1953]) Philosophical investigations. Oxford: Blackwell.

Zasloff, J.L. (1973) The Pathet Lao: leadership and organisation. Lexington

MA: Lexington Books.

\section{End Notes}

\footnotetext{
${ }^{1}$ Exceptions would include Parker (2004) and Kempster and Steward (2010).

${ }^{2}$ In their critical responses to Sidnell and Enfield's article, Levitt (2012) and Zinken (2012) both question the extent to which 'personal goals' are independent of a linguistically mediated social order. I am sympathetic to this critique as it seems to me that what we might recover analytically as a 'goal' must, itself, be perceptually and linguistically mediated.

${ }^{3}$ See Bartlett (2011) for an overview of agricultural extension in Laos.

${ }^{4}$ Source: Lao Statistics Bureau [http://www.nsc.gov.la accessed 19.06.13].

${ }^{5}$ King and van de Walle note that, 'There are several ethnic classification systems in Lao PDR and depending on the system used the number of ethnic groups vary... An alternative classification that is commonly used is based on geographic location. Hence, Tai-Kadai is called Lao Loum or Lao people of the valleys; Mon-Khmer are Lao Theung or the Lao people of the hillsides, and Tibeto-Burman and the Hmong-Mien are the Lao Soung or Lao people of the highlands'. (2010: 2, Fn 1).
}

${ }^{6}$ All Lao names are in this paper are pseudonyms used to protect the identity of research participants

${ }^{7}$ The terms emic and etic have been adopted and adapted from linguistics (Pike, 1993) by social anthropologists to distinguish between indigenous applications of concepts and categories (emic operations) and researchers' application of concepts and categories in the theorization and analysis of observed conduct (i.e., etic operations). See Harris (1976) for a discussion of the etic/emic distinction in anthropology.

${ }^{8}$ After his death, the LPRP tried, with limited success, to create a Kaysone 'cult' along the lines of Mao Tse Tung in China and Ho Chi Minh in Vietnam.

${ }^{9}$ I should note that in other contexts, e.g., infrastructure projects, central resourcing of five-year plans would be more likely to be forthcoming and thus the planning exercise would be more meaningful to stakeholders. In the agricultural sector, however, the picture is very different. 